\title{
Unsicherheit do século XXI: o ensino e aprendizagem da leitura e da escrita em língua portuguesa em São Paulo
}

\author{
Nilce da Silva \\ Patrícia Claudia da Costa Fridman \\ Universidade de São Paulo, São Paulo, Brasil
}

\begin{abstract}
Resumo: Este artigo tem como objetivo discutir os processos de ensino e aprendizagem da leitura e escrita em língua portuguesa, atualmente, em São Paulo. Ele se ancora nos conceitos de D. Winnicott, descrevendo, com base nos postulados de Bauman, a sociedade em que se vive suas regras, princípios e valores da "modernidade líquida", objeto destas reflexões - que interferem no resultado das relações pedagógicas, promovendo o aumento da atenção para questões advindas destas dificuldades; defende-se a "criatividade" aliada à "confiança" como condições mínimas para estabelecimento de clima afetivo e social adequado ao ensino e aprendizado da língua portuguesa, construindo caminhos para a Pedagogia deste novo milênio.
\end{abstract}

Palavras-chave: Aprendizagem. Criatividade. Língua portuguesa. Segurança.

\section{Unsicherheit in the XXI century: the teaching and the learning of reading and writing of portuguese language in Sao Paulo}

\begin{abstract}
The objective of this paper is to discuss the teaching and learning process of reading and writing in Portuguese language, nowadays, in Sao Paulo. It is anchored in the Winnicott's concepts, describing, based on Bauman's postulates, the society where we live - its rules, principles and implemented values of the "liquid modernity", the object of these reflections - that affect the result of the pedagogical relations, promoting the increase attention about questions concerning these difficulties; we defend the "creativity" and the "confidence" as minimum conditions to establish an affective and social climate adjusted to teaching and learning Portuguese language, constructing ways for Pedagogy in this new millennium.
\end{abstract}

Keywords: Apprenticeship. Creativity. Portuguese language. Security.

\section{Unsicherheit del siglo XXI: la enseñanza y el aprendizaje de la lectura y de la escritura en lengua portuguesa en San Pablo}

\begin{abstract}
Resumen: Este artículo tiene como objetivo discutir los procesos actuales de la enseñanza y aprendizaje de la lectura y escritura en lengua portuguesa, en San Pablo. Apoyados en conceptos de D. Winnicott, describiendo, con base en los postulados de Bauman, la sociedad en que se vive - sus reglas, principios y valores implementados, de la "modernidad liquida" que será objeto de esta reflexión - que interfieren en los resultados de las relaciones pedagógicas, promoviendo aumento de la atención para cuestiones resultado de estas dificultades. Defiendes la "creatividad" unida a la "confianza" como condiciones mínimas para establecer un clima afectivo y social adecuado para la enseñaza y aprendizaje de la lengua portuguesa, construyendo caminos para la Pedagogía de este nuevo milenio.
\end{abstract}

Palabras clave: Aprendizaje. Creatividad. Lengua portuguesa. Seguridad. 


\section{Introdução}

O campo da Educação tem sido marcado pelo crescimento das inúmeras discussões acerca dos motivos pelos quais um número cada vez maior de alunos não aprende a ler e a escrever em língua portuguesa após vários anos de escolarização. $\mathrm{O}$ excerto abaixo, retirado de publicação oficial da prefeitura do município de São Paulo acerca do Programa Ler e Escrever - corrobora essa constatação:

A Prefeitura de São Paulo, por intermédio da Secretaria Municipal de Educação (SME), inicia neste ano letivo (2006) o programa Ler e Escrever - prioridade na escola Municipal. O programa, que foca na qualidade do ensino, é resultado de um esforço da SME, através da Diretoria de Orientação Técnica (DOT), para reverter o fato de grande parte dos alunos da rede não dominar o sistema de escrita ao final do $1^{\circ}$ ano do Ciclo I, enquanto os do Ciclo II precisam aprimorar suas competências na área da leitura e escrita para enfrentarem os desafios hoje colocados pela sociedade.

Embora não existam dados oficiais que mostrem o número de alunos que terminam o $1^{\circ}$ ano do Ciclo I sem os conhecimentos mínimos necessários de leitura e escrita, uma pesquisa por amostragem realizada pela SME revela que existem escolas que chegam a ter até $30 \%$ de alunos que não escrevem convencionalmente no $3^{\circ}$ ano e que cerca de $17 \mathrm{mil}$ ficaram retidos em 2005 ao final do Ciclo I. No sistema de ensino da rede pública, o modelo adotado é de progressão continuada no ciclo ${ }^{1}$.

Diante deste quadro, vários são os eixos em que articulam os diferentes debates sobre o "fracasso" do ensino e da aprendizagem da língua portuguesa. Dentre eles, destacam-se os seguintes:

a) Discussão centralizada na questão das metodologias de ensino, ou seja, nas diferentes maneiras de se ensinar.

b) Produção acerca das políticas públicas educacionais.

c) Debates sobre o aparecimento do computador e da Internet, assim como, de outros avanços tecnológicos.

\footnotetext{
${ }^{1}$ Retirado em 15 agosto 2006, de http://www.prefeitura.sp.gov.br/ portal/a_cidade/noticias/index.php?p=7831/
}

d) Estudos que dialogam com os demais eixos e os sustentam, constituídos por discursos acerca dos "problemas de aprendizagem".

e) Polêmicas e discussões em torno da "formação de professores".

Com relação ao primeiro deles, especificamente na área da alfabetização em língua portuguesa, o debate acerca dos métodos de ensino resulta de longa data (Mortatti, 1999, 2005, 2006; Soares, 1991) quando, de modo caloroso, os defensores do método analítico contrapunham-se aos do sintético, até que surgiram outros proponentes e adeptos apresentando a possibilidade de um tanto analítico como sintético.

Na década de 80, com os trabalhos de Emília Ferreiro (Ferreiro \& Teberosky, 1986; Ferreiro, 1985/ 1992), uma revolução em termos de metodologia do ensino ocorreu, na medida em que o construtivismo concepção teórica acerca de como o ser humano chega ao conhecimento da realidade exterior - foi compreendido por muitos docentes como um método de ensino devido a uma intensa produção de discursos - de diferentes fontes - ingênuos, maldosos e, acima de tudo, equivocados. Deste modo, estes profissionais, alfabetizadores tiveram suas práticas pedagógicas, assim como suas pessoas, em última análise, destruídas, pois, praticamente tudo o que faziam em sala de aula foi considerado ultrapassado. Recentemente, inclusive nos meios de comunicação de grande circulação, acompanharam-se as farpas trocadas entre a pesquisadora argentina Emilia Ferreiro e adeptos dos que seguem uma vertente teórica divergente (Capovilla, Gutschow \& Capovilla, 2004; Capovilla, Capovilla, Trevisan, \& Rezende, 2006), ou seja, que apostam na utilização do método fônico para o ensino das primeiras letras como ideal, segundo os autores, para a promoção da aprendizagem conforme pesquisas de âmbito internacional.

No que se refere às políticas educacionais, muitos são os preocupados com a necessidade da sustentação das práticas em salas de aula por políticas públicas, com o objetivo fundamental de garantir a qualidade do ensino (Gentili, Suaréz, Stubrin, \& Gindin, 2005; Haddad, 2003; Paro \& Dourado, 2001), alertando para a descontinuidade das mesmas e a conseqüente impossibilidade de alcançarem os objetivos propostos. 
Com relação ao outro eixo destacado acima que abrange discussões acerca das mídias mais recentes, especificamente o computador e a Internet, há um grande número de trabalhos (Almeida, 2006; Soares, 2002) que apontam o magnetismo e sedução das novas mídias e a necessidade de a escola aproveitar estas ferramentas em seu cotidiano, inclusive para alfabetizar.

O quarto grupo de debates (Patto, 1988, 1990, $1999,2000)$ tem patologizado a aprendizagem e naturalizado ou biologizado as questões sociais, a partir do desenvolvimento dos estudos do cérebro promovidos já na Primeira Guerra Mundial, na Europa, e nos Estados Unidos. Assim, educadores, psiquiatras e neuro-psiquiatras passaram a se preocupar com as variantes biológicas que interferem na aprendizagem ${ }^{2}$.

Finalmente, considerando-se as mudanças da metodologia de ensino da alfabetização da década de 80 , os adventos midiáticos apresentados, as descontinuidades das políticas públicas do Estado brasileiro, e ainda, os discursos acerca de diferentes patologias que podem acometer os alunos, as discussões sobre a formação de professores crescem vertiginosamente sob a égide da formação continuada (Chamlian, 1996; Mortatti, 2003; Penin, 2001; Soares, 2001a, 2001b, 2002).

Entretanto, apesar de sérios estudos existentes nesta área, faz-se mister a preocupação com o contexto sócio-emocional do ensino e da aprendizagem por meio da análise, especialmente, das características da sociedade em que se vive, conforme exposto adiante. Desta forma, há que se levar em consideração que muitas das ações (sejam políticas públicas; cursos de formação de professores; mudanças na metodologia de ensino da língua portuguesa; introdução das mídias nas unidades escolares) ocorrem movidas por questões restritas ao consumo, ao comércio, em suma, ao dinheiro, e acabam, obviamen-

\footnotetext{
${ }^{2}$ Decorrentes destes estudos, hoje, diversas palavras são utilizadas para se referirem aos "problemas de aprendizagem". Dentre tantas, pode-se citar: distúrbio, transtorno, anormalidade, patologia, síndrome hipercinética, hiperatividade, disfunção cerebral mínima, transtornos específicos do desenvolvimento das habilidades escolares, transtornos do desenvolvimento psicológico, específico da leitura, do soletrar, transtorno específico de habilidades aritméticas, transtorno misto das habilidades escolares.
}

te, por distanciar a tríade necessária para o ensino e a aprendizagem: aluno, professor e conhecimento.

Com esta perspectiva, apresentam-se valores e princípios da megalópole São Paulo para que se possa discutir a "confiança" e a "criatividade" como elementos indispensáveis para que os processos de ensino e aprendizagem sejam iniciados e cheguem a se constituir respectivamente em "causa" e "efeito", ainda que, como se sabe, são distintos e, inúmeras vezes, independentes ${ }^{3}$.

Parte I - São Paulo: valores da grande cidade no século $X X I$

São Paulo - 1.525 quilômetros quadrados - é a maior cidade brasileira e da América do Sul e a quarta maior do planeta. De acordo com Lorenzoni (2006), o Instituto Brasileiro de Geografia e Estatística (IBGE) indica que a mesma tem 10,5 milhões de habitantes. Desta forma, abriga mais de $5 \%$ do povo brasileiro.

Em 2000, eram quase três milhões de lares e quatro mil escolas de nível fundamental e médio.

São Paulo tem mais de 7,1 milhões de eleitores: mais do que o total de habitantes do Rio de Janeiro (5,8 milhões), a segunda mais populosa cidade do país.

Conforme citação de Lorenzoni (2006), segundo a Associação Nacional dos Fabricantes de Veículos Automotores (Anfavea), de cada quatro que circulavam em 1997 no Brasil, um estava na capital paulista. Isto porque o transporte público é ineficiente. A cidade tem uma frota de cerca de cinco milhões de carros (licenciados) e uma circulação diária de aproximadamente três milhões de veículos. A malha viária total é de cerca de 14 mil quilômetros (dá para ir de Porto Alegre a Natal 3,5 vezes) e os motoristas paulistanos podem atravessar mais de 55 mil cruzamentos.

Frente a estes dados, conclui-se que os habitantes desta cidade vivem numa prisão dentro dos seus carros cotidianamente. O fluxo de veículos é desordenado e caótico. Além disto, tendo em vista o

\footnotetext{
${ }^{3}$ Ainda que freqüentemente utilizado, o binômio ensino

- aprendizagem não traduz uma relação perfeita de causa e efeito, pois, muitas vezes, aprende-se sem ser ensinado; e ensina-se, sem que alguém aprenda. Para maior aprofundamento acerca do assunto, sugere-se a leitura de obras de Thomas F. Green, professor de Filosofia da Educação da Syracuse University.
} 
dinamismo da cidade e suas intensas relações sócioeconômicas, todos têm pressa e precisam chegar logo. Decorrente desta necessidade de rapidez, uma das consequiências observadas é um trânsito extremamente agressivo e perigoso.

Vivendo num labirinto ameaçador, muitas são as estratégias de sobrevivência dos paulistanos. Os mais abastados fazem uso de helicópteros. Outra parcela da população utiliza uma das invenções exigidas pelo caos urbano: a profissão "moto-boy". Neste caso, o profissional é, geralmente, um jovem rapaz que faz entregas e serviços de moto pela cidade, "cortando" o trânsito e poupando muitos motoristas destas atividades; a profissão se expande, pois TODOS têm a rapidez como objetivo.

Não só no que diz respeito à mobilidade espacial, os habitantes de "Sampa", como ficou consagrada em verso e prosa, desejam libertar-se de todo o tipo de grilhão que obstrui ou impede seus movimentos para que se sintam soltos para suas ações. "Sentir-se livre" significa não experimentar dificuldade, obstáculo, resistência ou qualquer outro impedimento aos movimentos pretendidos ou concebíveis. Assim, há todo o tipo de serviço 24 horas por dia: hotéis para cães, casas de repouso, baby sitters. São facilidades disponíveis para que a população economicamente ativa possa se livrar de cães, idosos, crianças e de todos aqueles que possam obstaculizar seus movimentos.

Destaca-se ainda que, de acordo com a matéria de Lorenzoni (2006), a "Cidade da Garoa" tem mais de 50 shopping centers e 30 ruas de comércio especializado, repondendo a $20 \%$ das vendas de varejo e a $9,2 \%$ dos pontos de vendas de todo o Brasil.

Com relação ao lazer, Lorenzoni (2006) destaca as 265 salas de cinema, 92 teatros, mais de 70 museus, 11 centros culturais, além de salas de exposições e centenas de danceterias e barzinhos. A cidade é conhecida como a "Capital Mundial da Gastronomia" pois tem cerca de 12,5 mil restaurantes e 15 mil bares, cifras maiores do que as de Paris. É basicamente o Turismo de Negócios que movimenta 90 mil eventos por ano na cidade, com 15 milhões de participantes, sendo um evento a cada seis minutos na capital paulista, e das 170 feiras organizadas por ano no
Brasil, 107 são realizadas em São Paulo. Para receber tanta gente, há 50 mil vagas nos hotéis.

Outro indicador importante destacado por Lorenzoni, vem da Bolsa de Mercadorias e Futuros que é a sexta do mundo em volume de contratos negociados, com lances médios diários de US\$ 1,8 bilhão.

Sendo assim, a cidade de São Paulo está, sem dúvida, na fase do capitalismo leve - muito bem estudada pelo sociólogo polonês Bauman (1998, 2000, 2001), na qual existem muitas possibilidades, ao mesmo tempo, para todos. Em outras palavras, São Paulo é cidade da "(super) ponte aérea": do motoboy, do MSN, do skype, dos e-mails, da web, do delivery.

Como resposta às possibilidades de liberdade, os moradores, no anonimato da megalópole, têm a sensação de impotência sem precedentes na medida em que, no anseio pela liberdade, eles se encontram por sua própria conta e risco em meio ao concreto. A responsabilidade é deixada às energias individuais, favorecendo a solução biográfica das contradições sistêmicas. Desta forma, como todos estão sem tempo e preocupados com inúmeras atividades, poucos são os que têm tempo e disponibilidade para o amigo, o próximo; o vizinho é um desconhecido, quando não um inimigo.

Frente a estes dados que demonstram o grande fluxo da cidade em diferentes domínios (carros, pessoas, transações, acertos, encontros, conhecimento, negócio, dentre outros), pode-se afirmar que São Paulo é nitidamente uma cidade do século XXI ou, nas palavras de Bauman, uma cidade na modernidade líquida, pois, nesta época atual da história de parte da humanidade:

Os fluidos se movem facilmente. Eles 'fluem', 'escorrem', 'esvaem-se', 'respingam', 'transbordam', 'vazam', 'inundam', 'borrifam', 'pingam', são 'filtrados', 'destilados'; diferentemente dos sólidos, não são facilmente contidos - contornam certos obstáculos, dissolvem outros e invadem ou inundam seu caminho[...]. Associamos 'leveza' ou 'ausência de peso' à mobilidade e à inconstância (Bauman, 2001, p. 8)

Sempre na direção da fluidez e rapidez, tendo em vista as transações comerciais aqui apontadas, o consumir ganha enorme importância para os seus habitantes, permitindo que a mão invisível do mercado atue no sentido de transformar os luxos de hoje em 
necessidades do amanhã. Assim, na "Terra da Garoa", cada um dos seus habitantes, cada consumidor, vive em estado de auto-exame minucioso, autorecriminação, e depreciação permanentes, num fluxo de ansiedade contínua, já que consumir em um mercado de ininterruptas novidades - inclusive simbólicas, tais como: cursos, palestras, seminários, oficinas, congresos - torna-se, praticamente, uma tarefa sobre-humana.

Nesse contexto, o trabalho não é mais um porto seguro, nem fundamento da vida em sociedade, sobretudo o da imensa massa dos menos favorecidos economicamente. Para Bauman (2001), estes homens e mulheres que compõem o substrato social do movimento operário

[...] tendem a ser as partes mais dispensáveis, disponíveis e trocáveis do sistema econômico. Em seus requisitos de empregos não constam habilidades particulares, nem a arte da integração social com clientes - e assim, os mais fáceis de substituir; têm poucas qualidades especiais que poderiam inspirar seus empregadores a desejar mantê-los a todo o custo; controlam, se tanto, apenas parte residual do poder de barganha. Sabem que são dispensáveis, e por isso não vêem razões para aderir ou se comprometer com seu trabalho ou entrar numa associação mais durável com seus companheiros de trabalho. Para evitar frustração iminente, tendem a desconfiar de qualquer lealdade em relação ao local de trabalho e relutam em inscrever seus próprios planos de vida em um futuro projetado para a empresa. É uma reação natural à "flexibilidade" do mercado no trabalho que, quando traduzida na experiência individual da vida, significa que a segurança de longo prazo é a última coisa que se aprende a associar ao trabalho que se realiza (174).

Como consequiência desta liquidez desmedida, o tempo da cidade é o do fim da era do engajamento mútuo: todos estão ocupados o tempo todo. A agenda está cheia especialmente para aqueles que, no momento, não podem oferecer alguma espécie de vantagem. Para os "indesejados", oferece-se toda espécie de resposta vinda de um aparelho eletrônico. Estas máquinas, portanto, colaboram para que o descompromisso entre as pessoas seja uma norma: a secretária eletrônica ligada, o correio eletrônico "que não funciona bem", o "computador que pegou vírus", a caixa postal do celular são barreiras colocadas entre aqueles que não querem se atender
(Silva, 2004). Todos participam de muitos projetos ao mesmo tempo e não se observa, salvo em raríssimas exceções, o nascimento e muito menos o crescimento de fortes vínculos entre as pessoas que se acotovelam na megalópole.

Do ponto de vista aqui adotado, as relações humanas na "Selva de Pedra" têm os seguintes aspectos: a fuga, a astúcia, o desvio e a evitação, a efetiva rejeição de qualquer confinamento territorial, com os complicados corolários de construção e manutenção da ordem, e com a responsabilidade pelas conseqüências de tudo, bem como com a necessidade de arcar com os custos (Bauman, 2001, p. 18).

Deste modo, a procrastinação - considerada há pouco tempo como demonstração de displicência, indolência ou lassidão - torna-se posição ativa e, portanto, proposital. A identidade de palimpsesto encontra terreno fértil para sua constituição:

Essa é a identidade que se ajusta ao mundo em que a arte de esquecer é um bem não menos, se não mais, importante do que a de memorizar, em que esquecer, mais do que aprender, é a condição de contínua adaptação, em que sempre novas coisas e pessoas entram e saem sem muita ou qualquer finalidade do campo de visão da inalterada câmara da atenção, e a própria memória é como fita de vídeo, sempre pronta a ser apagada a fim de receber novas imagens, alardeando uma garantia para toda a vida exclusivamente graças a essa admirável perícia de incessante auto-obliteração (Bauman, 1998, p. 36).

Assim também, as questões públicas perdem espaço para a discussão, pois:

[...] o aumento da liberdade individual pode coincidir com o da impotência coletiva na medida em que as pontes entre a vida pública e privada são destruídas ou, para começar, nem foram construídas; colocando de outra forma, não há uma maneira óbvia e fácil de traduzir preocupações pessoais em questões públicas e, inversamente de discernir e apontar o que é público nos problemas privados (Bauman, 2000, p. 10).

E por isso, tem-se questões apenas tratadas em público, o que não significam que sejam públicas.

A chance de mudar isso depende da ágora - esse espaço nem privado nem público, porém mais precisamente público e privado ao mesmo tempoem que os problemas particulares se encontram de modo significativo.... O meio de vida, essa rocha em que se devem assentar todos os projetos para 
serem viáveis, fazendo sentido e reunindo a energia necessária para se realizarem (ou, pelo menos, tentarem isso), tornou-se inseguro, errático e inconfiável. O que os advogados dos programas de 'bem-estar para trabalhar' deixam de considerar é que a função do meio de vida não é apenas garantir o sustento diário para os empregados e seus dependentes, mas - e não menos importante -dar segurança existencial sem a qual a liberdade nem a vontade de auto-afirmação são concebíveis, o que é o ponto de partida de toda a autonomia. O trabalho no seu formato atual não pode dar essa segurança, mesmo se consegue repetidamente cobrir os gastos com a sobrevivência. A estrada que parte do bem-estar para o trabalho leva da segurança à insegurança ou de menor para maior insegurança (Bauman, 2000, p. 182).

Não menos sintomática é a situação vivenciada pelos paulistanos em 2006, em que o crime organizado pelo Primeiro Comando da Capital (PCC) assustou os moradores da megalópole (incendiando ônibus, disparando contra policiais nas ruas, distribuindo bombas de fabricação caseira pelas ruas da cidade, dentre outras ações), colocando de modo explícito as questões que estão abertas como chagas ao público e não tratadas, especificamente, como de "segurança pública". A Tribuna do Interior (2006) revela a situação:

PCC completa três ondas de ataque:

O PCC, que controla o crime organizado desde as prisões de São Paulo, desafiou as autoridades por três vezes nos últimos meses, com sangrentos ataques contra forças de segurança, bancos, comércios e ônibus de serviço público.

O primeiro deles, ocorrido em meados de maio, deixou 133 mortos, em sua maioria policiais, agentes carcerários e delinqüentes; foi uma represália da facção contra a mudança de seus líderes para prisões de segurança máxima.

Em julho, a organização criminosa voltou a atacar em vários municípios de São Paulo, com um saldo de oito mortes; seis supostos delinqüentes foram mortos pela Polícia na reação a uma nova ofensiva. Foram incendiados quatro ônibus, mas a polícia não estabeleceu se os autores pertencem à facção criminosa que, segundo as autoridades, tinha um plano para lançar novos ataques no final de semana.
A polícia descobriu um plano do grupo para seqüestrar políticos em São Paulo, e o ocorrido deixa em evidência que a imprensa agora é um dos alvos dos criminosos, segundo especialistas em política e luta criminal ${ }^{4}$.

Em suma, o clima sócio-emocional e cultural da cidade pode ser definido pela palavra alemã Unsicherheit: "falta de segurança, de certeza e de garantia". Ver-se-á que o modo como Bauman utilizou este conceito para refletir sobre questões dessa era e, a partir de sua análise, poder-se-á analisar alguns percalços relacionados ao ensino e ao aprendizado na escola contemporânea.

\section{Parte II - Unsicherheit como fundamento} das impossibilidades de ensino e de aprendizagem

Implícita ou explicitamente, as instituições políticas vigentes vivem hoje um "processo de abandono ou de diminuição do seu papel de criadoras de código e de agenda" (Bauman, 2000) e, neste contexto, o mercado de consumo é o que regula as agendas. Sendo assim, parafraseando o referido autor, pouco a pouco, a Sicherheit - segurança, certeza e garantia - oferecida pela escola pública está desaparecendo.

Neste caso, a comunidade escolar ligada à alfabetização, no âmbito da rede pública de ensino, tem diminuída cotidianamente sua segurança, ou seja, não sabe se aquilo que foi obtido continuará em seu poder: o emprego, a sala de aula e o saber ensinar, do lado dos professores; e, os alunos, por sua vez, não sabem, por exemplo, até quando aquela será sua professora, se continuará estudando ou não, se sua sala de aula se manterá aberta, dentre outros medos. Também não têm mais certezas, não sabendo diferenciar entre o que é razoável ou tolo, digno de confiança ou traiçoeiro, especialmente no que diz respeito aos modismos educacionais, para os professores, e ao conteúdo ministrado em aula, para os discentes. Finalmente, não têm a menor garantia de que nada será uma ameaça ao seu corpo, inclusive nas relações pedagógicas sempre mais violentas,

\footnotetext{
4 Retirado em 24 agosto 2006, de http://www.tribunadointerior.com.br/ index.php?pag $=$ noticias\&id_noticia $=11001 \&$ conjunto $=\& i d \_$caderno $=$ 8\&id_usuario $=\&$ noticias.
} 
inseridas em uma sociedade, como acima exposta, com o mesmo perfil:

Os três ingredientes da Sicherheit [segurança, certeza e garantia] são condições para a autoconfiança de que depende a capacidade de pensar e agir racionalmente. A ausência ou carência de um desses elementos tem basicamente o mesmo efeito: dissipação da autoconfiança, perda de confiança na própria capacidade e nas intenções dos outros, uma crescente incapacitação, ansiedade, esperteza e a tendência de buscar defeitos, de apontá-los, a arranjar bodes expiatórios e a agredir. Todas essas tendências são sintomas de uma corrosiva desesperança existencial: a rotina diária agora rompida e não confiável - e que, se seguida de forma descarada, pouparia ao autor a agonia de ter que optar sem parar-força um exame apreensivo, revelando os riscos que implica; pior, continuamente, as respostas e reações aprendidas, adquiridas, perdem validade rápido demais para se condensarem em hábitos e congelarem em comportamentos rotineiros. A probabilidade de consequiências indesejáveis que emana de cada opção e a consciência de que essas não podem ser calculadas com precisão produzem menos a ânsia de melhor controlar os resultados da própria ação (que se torna uma perspectiva nada realista) do que o desejo de se garantir contra os riscos envolvidos em todas as ações de se livrar da responsabilidade pelos resultados (Bauman, 2000, p. 26).

Deste modo, nesta São Paulo, grupos criminosos politicamente organizados dominam os corpos de alunos e professores que verdadeiramente correm riscos e, por isso dentre outros fatores, sentem-se inseguros.

Os empregos públicos, tanto dos professores da rede estadual como municipal de ensino fundamental, já não são mais garantidos, há tantos degraus na carreira docente para a efetivação que tal probabilidade torna-se diminuta. Além disto, a aposentadoria do funcionalismo público, que antes era vista como uma forma de segurança, hoje em dia, não tem mais este caráter, tendo em vista as sucessivas mudanças no sistema previdenciário, incluindo o aumento do número de trabalhos e a possibilidade de ter o salário reduzido. Com relação aos pais dos alunos, a situação é igualmente instável e precária.
A situação de instabilidade é a mesma na maioria dos estabelecimentos particulares, ressalvadas as características específicas. O emprego dos professores é cada vez mais fluido, temporário, incerto e inseguro; os núcleos familiares com seus respectivos empregos e rendimentos, também o são.

Em suma, o alfabetizador e os alfabetizandos vivem a violência estrutural do desemprego e das demais mazelas sociais ou têm um emprego precário com demissão à vista.

Atrelando-se todos esses fatores às questões psicanalíticas, vistas a seguir, pode-se dizer que o aprendizado da leitura e da escrita da língua portuguesa fica praticamente inviável e a Unsicherheit instala-se.

O mais sinistro e doloroso dos problemas contemporâneos pode ser melhor entendido sob a rubrica Unsicherheit, termo alemão que funde experiências para as quais outras línguas podem exigir mais palavras - incerteza, insegurança e falta de garantia. O curioso é que a própria natureza desses problemas é poderoso impedimento aos remédios coletivos: pessoas que se sentem inseguras, preocupadas com o que lhes reserva o futuro e temendo pela própria incolumidade não podem assumir os riscos que a ação coletiva exige. Faltalhes a coragem de ousar e tempo para imaginar formas alternativas de convívio; e estão preocupadas com tarefas em que não podem sequer pensar, quanto mais dedicar sua energia, e que só podem ser empreendidas em comum (Bauman, 2000, p.13).

Assim, para o autor, há que se desprezar a liberdade individual, inclusive a que os alunos ainda jovens têm hoje, em que a imaginação é desestimulada, colocando a todos em situação de impotência. Há que compreender que a liberdade individual é resultado de trabalho coletivo que não significa apenas um "somar de pequenas vozes".

E ainda, conforme Bauman (2000, p.32), "as duas coisas de que mais se tem certeza hoje em dia é que há pouca esperança de serem mitigadas as dores das atuais incertezas e que mais incerteza ainda está por vir."

É neste contexto afetivo-social que se propõe a discutir os processos de ensino e de aprendizagem. Adianta-se que em nada ele é favorável à relação 
pedagógica. E, por isso, faz-se mister apresentar alguns conceitos, nos limites deste artigo, de um dos pensadores da natureza humana que se preocupou com a "segurança" oferecida pelo "meio ambiente" como fundamental para os processos de ensino e de aprendizagem. É ele: Donald Woods Winnicott.

\section{Parte III - Criatividade e confiança: bases da aprendizagem}

Muitos são os grandes nomes da Pedagogia aos quais se poderia recorrer para alicerçar a afirmação de que "confiança" e "criatividade" são "emoções" que fundamentam as relações pedagógicas e, conseqüentemente, os atos de ensinar e o processo de aprender. Destaca-se o autor Winnicott, especialmente quando apresenta o "espaço de criação" e a "necessidade do ser humano de ter confiança no meio" para se desenvolver.

A afirmação feita reiteradamente por Winnicott, em inúmeros de seus trabalhos e cartas, de que lidar com o meio ambiente é a grande tarefa humana, pode ser considerada como uma síntese da sua obra. Nesta direção, ele afirma que o bebê tem que ser o criador do seio da mãe (Winnicott, 1990), e que quando ela é suficientemente boa, permite este estado de ilusão para seu filho. Assim, de acordo com este teórico, nas primeiras semanas, o bebê pensa que ele é o próprio seio da mãe, pois quando mama a sua satisfação é total, é uterina, ou seja, é de completude e satisfação. Aos poucos, com o distanciamento da mãe e todo o processo de desenvolvimento neurológico sofrido por ele, começa a perceber que o seio materno não está sempre à disposição e que, portanto,não é ele, bebê. A distância entre mãe (realidade externa) e bebê (eu interior) foi definida por Winnicott pelo conceito de espaço de criação ou espaço potencial. Na medida em que o bebê percebe que ele não é a mãe e que entre ele e ela existe um "espaço" - físico e temporal - ou ainda que a mãe é realidade exterior a ele - o bebê faz inúmeras tentativas para preencher este "espaço" e diminuir a sua angústia pela espera do seio materno. Para preencher este espaço, ele precisa "inventar" algo, colocar algum "substituto" da mãe enquanto a aguarda, ou seja, criar para não sofrer, para não ter traumas, especialmente, o tão propenso, do desamparo, do abandono. E assim, o bebê, enquanto a mãe não vem, ao invés de se sentir abandonado, pode se contentar com uma mamadeira, uma chupeta, um paninho ou mesmo com o seu dedo. Estes objetos que se encontram entre a espera dele pela mãe e a chegada dela, objetos que minimizam a angústia foram chamados por Winnicott de objetos transicionais, e o despertar da criatividade para a solução da angústia da separação, conceituado como fenômenos transicionais.

Segundo o referido psicanalista inglês (1983a, 1965/1983b, 1964/1985, 1988/1990, 1993), a criatividade simbólica é a manutenção, através da vida, de algo que pertence à experiência infantil: a capacidade de criar o mundo. Ou seja, a situação de ilusão - quando o bebê pensa que o seio da mãe é ele mesmo - e a situação de desilusão - quando percebe que não está sempre à disposição - repetese na relação que o ser humano estabelece ao longo da vida entre "ele" e a realidade exterior. E, sendo assim, para que este ser humano torne-se saudável, faz-se mister "criar", produzir fenômenos de transição.

Conforme Winnicott (1983a, 1965/1983b, 1964/ 1985, 1990, 1993), em sua originalidade, há que se entender que os objetos transicionais não pertencem totalmente à realidade interior do bebê, porém nela influenciam; nem ao mundo externo, propriamente dito, pois são substitutos da mãe que o bebê ainda crê que faz parte de si. Porém, são produtos culturais, tal como é o gesto. E assim, nas experiências transicionais, o bebê, a criança, o jovem e até mesmo o adulto pretendem um controle mágico do mundo que encontra lugar especialmente nas artes e na religião, no sentido mais amplo que o termo pode abarcar, espaços em que, em uma das passagens de suas obras, o ser humano pode usufruir do descanso necessário aos seres humanos em sua eterna tarefa de discriminar entre os fatos e as fantasias (Winnicott, 1990, p. 127).

Sendo assim, a integração entre realidade exterior e interior, tendo como elo o espaço transicional, que permite a criatividade por meio do uso dos objetos culturais à disposição dos homens e mulheres - propiciando espaço para o jogo - promove o sentimento de integração e de sanidade. 
Vale destacar ainda que Winnicott trata sempre da abordagem criativa à realidade externa e acredita que só é possível ser original na tradição. Caso contrário, trata-se de submissão, adaptação ou alucinação. A cultura é constitutiva do homem, que anseia por se desenvolver, participar e contribuir para o meio social e cultural em que está inserido. Necessita e busca inscrever sua subjetividade na realidade externa, utilizando sua vida imaginativa para transformá-la em objetos significativos.

Em síntese, a aprendizagem se dá nestas sucessivas e inúmeras relações entre o ser humano e o meio ambiente e, para tanto, a "confiança" é fundamental para que a "criatividade", no sentido winnicottiano possa se efetivar.

Nesta perspectiva, apenas face à relação confiante com o meio ambiente a elaboração cognitiva é possível; assim, conhecer é obra da criatividade a partir da relação feita no "espaço de criação".

Portanto, é o vínculo afetivo estabelecido entre o adulto e a criança - e mais tarde, reeditado na relação professor / aluno - que sustenta a etapa inicial dos processos de aprendizagem nos quais os seres humanos se envolvem, ao longo de sua vida, que qualificarão um ambiente como seguro ou não. E, desta forma, é a partir do vínculo com a mãe que a criança terá acesso ao mundo simbólico e, assim, conquistará avanços significativos em suas aprendizagens.

Em suma, ao recorrer às idéias de Winnicott sobre a relação do ser humano com seu meio, considera-se a aprendizagem - e também o "ensino" enquanto as ações de um professor para que seu aluno aprenda - como decorrentes da segurança e confiabilidade ambiental e da não-interrupção da continuidade desse processo. Além disto, Bauman e Winnicott também oferecem elementos para a reflexão sobre a criatividade como característica humana que somente pode emergir com toda a sua força em um ambiente seguro. Não obstante, conforme assinalado antes, São Paulo não é ambiente seguro. Por isso, a seguir serão discutidas as possibilidades e limites para que ocorram o ensino e a aprendizagem da leitura e da escrita da língua portuguesa nos dias de hoje em São Paulo.

\section{Considerações finais}

Tendo em vista as condições aqui apresentadas para que a aprendizagem e o ensino da língua portuguesa ocorram, faz-se latente o questionamento sobre as atuais condições estruturais das escolas públicas da cidade de São Paulo: resta alguma possibilidade para que sejam palcos de tais processos? À primeira vista, as chances, para tanto, são a cada dia menores.

Se o professor, o alfabetizador, neste caso, vem a ser para o aluno o mesmo que a mãe foi para o bebê ${ }^{5}$, conforme apontado anteriormente, que grau de segurança este alfabetizador - com instabilidade de emprego, que teve a segurança na sua formação minada, que precisa fazer cursos de formação a cada minuto livre da sua semana - pode oferecer a seus alunos? Praticamente nenhum.

Conforme exposto acima, a chance para mudar $\mathrm{o}$ atual quadro social, que inevitavelmente incide em questões particulares dos envolvidos no desafio do ensino e da aprendizagem da língua portuguesa na cidade de São Paulo, depende da ágora - esse espaço nem privado nem público, porém mais precisamente, entre público e privado ao mesmo tempo, em que os problemas particulares se encontram de modo significativo - isto é, não apenas para extrair prazeres narcisícos ou buscar alguma terapia através da exibição pública, mas para procurar coletivamente alavancas controladas e poderosas o bastante para tirar os indivíduos da miséria sofrida de maneira particular; espaço em que as idéias podem nascer e tomar forma como "bem público", "sociedade justa" ou "valores partilhados". Apesar de ter restado muito pouco destes espaços - que guardam semelhança com o "espaço de criação" apontado por Winnicott, pois é, ao mesmo tempo, "eu" e "não-eu" - é neles, tanto do ponto de vista individual como da perspectiva coletiva, que algo se poderá fazer para que a realidade não seja um imenso universo de empreiteiras ávidas pelo dinheiro.

\footnotetext{
5 Temos a impressão de que neste clima econômico e sócio-afetivo da cidade de São Paulo, até mesmo as mães têm falhado em termos de oferecer segurança a seus filhos. Nas palavras de Winnicott, as mesmas podem não estar sendo "suficientemente boas". Entretanto, por tratar-se de assunto complexo e para evitar a leviandade, não faremos incursões teóricas nesta direção.
} 
Desde o início, o bebê tem experiências maximamente intensas no espaço potencial existente entre o objeto subjetivo e o objetivamente percebido, entre extensões "do eu" e "do não eu". Nesse espaço potencial, na interação entre nada haver se não eu e a existência de objetos e fenômenos situados fora do controle onipotente, todo bebê tem sua experiência favorável ou desfavorável. A dependência é máxima. O espaço potencial acontece apenas por um sentimento de confiança dele, isto é, confiança relacionada à fidedignidade da figura materna ou dos elementos ambientais, sendo prova da fidedignidade que se está introjetando (Winnicott, 1971/1975). Assim, tanto os objetos culturais construídos pelo bebê na tentativa de minimizar a angústia surgida pela ausência da mãe, quanto a cultura mais ampla, do ponto de vista da sociedade, são essenciais na superação do atual estado de Unsicherheit em que se vive, na medida em que se compreende a cultura como a única atividade capaz de:

traçar limites e construir pontes, separar e unir, distinguir ou conectar com a 'natureza', por isso, sempre foi e sempre será a atividade de dar respostas às três perguntas referidas, que compõem um grande mistério: se é temporária a minha presença no mundo, por que estou aqui e com que propósito (se é que existe algum)? Foi esta charada que estimulou todo tipo de homem à ação frenética, muitas vezes tresloucada, que em fins do século XVIII recebeu o nome de cultura; e foi esse enigma que fez da cultura, com sua densa rede de explicações e consolos, o valor supremo o sine qua non, para as criaturas conscientes da sua mortalidade (Bauman, 2000, p. 40).

Sendo assim, e apesar de tudo, o professor alfabetizador poderá fazer com que seu aluno aprenda. Como Winnicott, afirma-se que é o professor que precisa se preocupar em explorar o espaço potencial entre ele e seu aluno, sendo confiável e fidedigno, podendo instaurar um espaço lúdico, seguro, apresentando informações onde o educando esteja pronto para recriá-las. O paradoxo "criadoencontrado" pode ser trabalhado nos processos de ensino e de aprendizagem para que o aluno se aproprie de conteúdos relevantes de forma singular e criativa, segundo suas concepções e necessidades. O professor precisa facilitar a transição, ajudá-lo a constituir objetos transicionais com os da cultura para depois poder estabelecer uma relação (de uso) mais objetiva com a tradição dominante. E, para finalizar, nesta criação, a ágora pode instaurar-se na sala de aula de modo que questões de natureza pública venham a ser tratadas em um espaço que é público, beneficiando os agentes envolvidos.

Remetendo a sala de aula ao status de ágora, como forma de ampliar as possibilidades de construção de um ambiente de confiança que vise à facilitação do ensino e da aprendizagem, pode-se valer do instigante alerta: "Há duas maneiras de atacar a ágora, ameaçar sua integridade e distorcer ou solapar seu papel" (Bauman, 2000, p. 93).

A integridade, como vista acima, está bastante comprometida por conta da conjuntura social e emocional na qual os sujeitos de ensino e de aprendizagem estão inseridos. Quanto ao papel do ambiente de aprendizado, prefere-se apontar a otimista via de re-significação que deve ser assumida pela comunidade que compõe o espaço público conhecido como sala de aula.

\section{Referências}

Almeida, F. J. (2006). Tecnologias da educação para a Cidade Educativa. Cadernos Cenpec, 1(1), 121-128.

Bauman, Z. (1998). O mal-estar da pósmodernidade (M. Gama, \& C. M. Gama, Trad.). Rio de Janeiro: Jorge Zahar Ed.

Bauman, Z. (2000). Em busca da política (M. Penchel, Trad.). Rio de Janeiro: Jorge Zahar Ed.

Bauman, Z. (2001). Modernidade líquida (P. Dentzien, Trad.). Rio de Janeiro: Jorge Zahar Ed.

Capovilla, A. G. S.; Gütschow, C. R. D., \& Capovilla, F. C. (2004). Habilidades cognitivas que predizem competência de leitura e escrita. Psicologia, 6 (2), 13-26.

Capovilla, A. G. S.; Capovilla, F. C.; Trevisan, B., \& Rezende, M. C. A. (2006). Natureza das dificuldades de leitura em crianças brasileiras com dislexia do desenvolvimento. Revista Acolhendo a Lingua Portuguesa: A alfabetização em foco, 1. Retirado em 24 agosto 2006, de http:// www.mocambras.org. 
Chamlian, H. C. (1996). Currículo do curso de Pedagogia da USP. Revista da Faculdade de Educação (USP), 2 (22), 131-157.

Ferreiro, E. (1992). Reflexões sobre alfabetização (H. Gonzalez, Trad.). São Paulo: Cortez. (Trabalho original publicado em 1985).

Ferreiro, E. \& Teberosky, A. (1986). Psicogênese da língua escrita (M. Lichtenstein, L. Di Marco, $\&$ M. Corso, Trad.) Porto Alegre: Artes Médicas.

Gentili, P., Suaréz, D., Stubrin, F., \& Gindin, J. (2005). Reforma educativa y luchas docentes en América Latina. In G. Frigerio, \& G. Diker (Ed.), Educar: Ese acto político (pp. 107-125). Buenos Aires: Del Estante Editorial.

Haddad, S. (Org.). (2003). O Banco Mundial e as políticas educacionais (Ação Educativa, Vol. 01). São Paulo: Editora Cortez.

Lorenzoni, R. (2006). A maior cidade da América do Sul. Retirado em 10 agosto 2006, de http:// sp450anos.terra.com.br/interna/0,,OI236169EI2551,00.html.

Mortatti, M. (1999). Método analítico, cartilhas e escritores didáticos: Ensino da Leitura Em São Paulo (1890-1920). História da Educação (ASPHE), 5 (3), 123-140.

Mortatti, M. (Org.). (2003). Formação de professores: Propostas para uma ação reflexiva no ensino fundamental e médio (Vol. 1). Araraquara: J. M. Editora.

Mortatti, M. (2005). Os sentidos da alfabetização (São Paulo -1876/1994) (Vol. 1). São Paulo; Brasília: Editora Unesp.

Mortatti, M. (2006). História dos métodos de alfabetização no Brasil. Portal Mec Seminário Alfabetização e Letramento Em Debate, Brasília. Retirado em 10 agosto 2006, de http:// www.mec.gov.br.

Paro, V. H., \& Dourado, L. F. (2001). Políticas públicas e educação básica. São Paulo: Xamã.

Patto, M. H. S. (1988). O fracasso escolar como objeto de estudo: Anotações sobre as características de um discurso. Cadernos de Pesquisa, 72-77.
Patto, M. H. S. (1990). A produção do fracasso escolar: Histórias de submissão e rebeldia. São Paulo: T.A. Queiroz.

Patto, M. H. S. (1999). Estado, ciência e política na Primeira República: A desqualificação dos pobres. Estudos Avançados, 13 (35), 167-198.

Patto, M. H. S. (2000). A produção do fracasso escolar: Histórias de submissão e rebeldia. São Paulo: Casa do Psicólogo.

Penin, S. T. S. (2001). A Formação de professores e a responsabilidade das Universidades. Estudos Avançados, 15(42), 317-332.

Prefeitura da Cidade de São Paulo. Prefeitura implementa o programa "Ler e Escrever" na rede municipal. Retirado em 15 agosto 2006, de http://www.prefeitura.sp.gov.br/portal/ a_cidade/noticias/index.php? $p=7831$.

Silva, N. (2004). Universidade e escola pública: Instituições totais na modernidade líquida. Pensamento \& Realidade, v. 15, 48-68.

Soares, M. B. (1991). Alfabetização: Em busca de um método? Tecnologia Educacional, 20, 07-13.

Soares, M. B. (2001a). Que professores de português queremos formar?. Movimento: Revista da Faculdade de Educação da UFF,(3),149-155.

Soares, M. B. (2001b). As pesquisas nas áreas específicas influenciando o curso de Formação de professores. In M. André (Org.), O papel da pesquisa na formação e na prática dos professores (pp. 91-105). Campinas: Papirus.

Soares, M. B. (2002). Novas práticas de leitura e escrita: Letramento na cibercultura. Educação e Sociedade, 81 (23), 143-160.

Winnicott, D. W. (1975). O Brincar e a realidade (J. O .A. Abreu, \& V. Nobre, Trad.). Rio de Janeiro: Imago Editora. (Trabalho original publicado em 1971).

Winnicott, D. W. (1983a). A família e o desenvolvimento individual (M. B. Cipolla, Trad.). São Paulo: Martins Fontes. 
Winnicott, D. W. (1983b). O ambiente e os processos de maturação (I. C. S. Ortiz, Trad.) Porto Alegre: Artes Médicas. (Trabalho original publicado em 1965).

Winnicott, D. W. (1985). A criança e seu mundo (A. Cabral, Trad.). Rio de Janeiro: Zahar Editores. (Trabalho original publicado em 1964).

Winnicott, D. W. (1990). Natureza humana (D. L. Bogomoletz, Trad.). Rio de Janeiro: Editora Imago.

Winnicott, D. W. (1993). Conversando com os pais (A. Cabral, Trad.). São Paulo: Martins Fontes.

PCC completa três ondas de ataques. Tribuna do interior. Retirado em 24 agosto 2006, de http:// http://www.tribunadointerior.com.br/ index.php?pag=noticias\&id_noticia $=11001 \&$ conjunto $=$ $\& i d \_$caderno $=8 \& i d \_u s u a r i o=\&$ noticias

Endereço para correspondência:

Nilce da Silva. Rua Antonieta Leitão, 209 Apto 12. Freguesia do Ó. CEP: 02925-160, São Paulo - SP, Brasil. E-mail: nilce@usp.br

Artigo recebido em 23/11/2006.

Aceito para publicação em 16/04/2007.

Texto produzido no âmbito das discussões do grupo de pesquisa, ensino e extensão Acolhendo Alunos em Situação de Exclusão Social e Escolar: o papel da instituição escolar, certificado pela USP. Apoio CNPq e FAPESP. Sítio: www.projetoacolhendo.org

Nilce da Silva é Professora Doutora da Faculdade de Educação da Universidade de São Paulo.

Patrícia Claudia da Costa Fridman é Mestranda em Educação pela Universidade de São Paulo. 